\title{
Air-Based Coaxial Dielectric Bamier Discharge Plasma Source for Pseudomonas aenuginosa Biofilm Eradication
}

\author{
Juliana Soler-Arango, ${ }^{a}$ Magalí Xaubet, ${ }^{\mathrm{b}, \mathrm{c}}$ Leandro Giuliani, ${ }^{\mathrm{b}, \mathrm{c}}$ \\ Diana Grondona, ${ }^{\mathrm{b}, \mathrm{c}, \mathrm{d}}$ \& Graciela Brelles-Mariñoa, ${ }^{\mathrm{a}}$ \\ ${ }^{a}$ Center for Research and Development of Industrial Fermentations, Consejo Nacional de \\ Investigaciones Científicas y Técnicas (CINDEFI, CCT-LA PLATA-CONICET), Facultad de \\ Ciencias Exactas, Universidad Nacional de La Plata, La Plata, Argentina; 'Universidad de \\ Buenos Aires, Facultad de Ciencias Exactas y Naturales, Departamento de Física, Buenos Aires, \\ Argentina; ${ }^{\circ C O N I C E T-U n i v e r s i d a d ~ d e ~ B u e n o s ~ A i r e s, ~ I n s t i t u t o ~ d e ~ F i ́ s i c a ~ d e l ~ P l a s m a-C O N I C E T ~}$ \\ (INFIP), Buenos Aires, Argentina; dUniversidad de la Marina Mercante (UdeMM), Facultad de \\ Ingeniería, Laboratorio de Micro y Nanofluídica y Plasma, Buenos Aires, Argentina \\ *Address all correspondence to: Graciela Brelles-Mariño, Center for Research and Development of Industrial \\ Fermentations, Consejo Nacional de Investigaciones Científicas y Técnicas (CINDEFI, CCT-LA PLATA-CONICET), \\ Facultad de Ciencias Exactas, Universidad Nacional de La Plata, Calles 47 y 115, 1900-La Plata, Argentina; Tel.: +54 \\ (221) 4833794; Fax: +54 (221) 4833794, E-mail: gracielabrelles@gmail.com
}

\begin{abstract}
Biofilms cause biofouling, pipe plugging, prostheses colonization, disease, and nosocomial infections. Bacterial biofilms are more resilient to sterilization methods than planktonic bacteria; therefore, better control methods are required. The use of gas discharge plasmas is an appropriate alternative because plasmas contain a mixture of reactive agents that are well known for bacterial decontamination. This study assesses culture medium-abiotic surface combinations leading to robust biofilms and tests an air-based coaxial dielectric barrier discharge (DBD) plasma source on Pseudomonas aeruginosa biofilms grown in continuous culture under those selected conditions. Biofilms were eradicated after a 15 -min plasma treatment, resulting in a CFU/mL decrease of $5.6 \log _{10}$ units. CFU/mL decreases of 1.6 and 2.7 $\log _{10}$ units were achieved after a 3-min plasma exposure to ambient and moistened air plasma, respectively, although viability assays showed that some cells were alive. Moistened-air plasma resulted in a faster biofilm inactivation, with decimal reduction times of 1.14 and 4.36 min. The coaxial DBD air-based plasma source presented here is effective for Pseudomonas biofilm inactivation, affordable because it does not rely on expensive gases, and easy to handle for indirect surface treatment. To the best of our knowledge, the search for the best combination medium surface leading to robust biofilms before plasma treatment has not been previously assessed.
\end{abstract}

KEY WORDS: biofilms, Pseudomonas aeruginosa, sterilization, biofilm eradication, nonthermal plasmas, air-based plasma, Pseudomonas biofilms

\section{INTRODUCTION}

Biofilms are microbial communities that grow attached to a surface and embed in a matrix composed of exopolysaccharides together with proteins and extracellular nucleic acids. Biofilms are present almost everywhere and, therefore, wherever there is a surface and some moisture, it is likely that a biofilm will develop. Biofilm formation takes place 
in several steps, starting with free-living (planktonic) bacteria that recognize a surface. Bacteria reversibly adsorb and then irreversibly attach to the surface. The attached cells grow, divide, and recruit additional planktonic cells that attach to the cells already present on the surface. This process results in the development of a mature biofilm with a particular architecture in which cell clusters and water channels among them form a primitive circulatory system. ${ }^{1}$ The emerging biofilm results in a tridimensional structure, where cells are protected by the matrix and cooperative interactions become important. ${ }^{2}$

Bacterial biofilms are of concern in industrial settings because they result in biofouling, equipment damage, contamination of water sources, pipe and duct plugging, and product contamination, to mention a few. They also cause prostheses colonization, tooth decay, and dental plaque and produce or contribute to diseases such as otitis media, cystic fibrosis, and Legionnaire's disease. ${ }^{3}$ As biofilms contaminate water sources, they could spread disease. ${ }^{4}$ Biofilms are also responsible for $\sim 90 \%$ of infections in humans, according to the National Institutes of Health (NIH), and $65 \%$ of nosocomial infections, according to the Centers for Disease Control (CDC). Biofilms are more resilient to typical decontamination/sterilization methods that are used for free-living bacteria due to their encased, protected tridimensional structure, in which the exopolysaccharide functions as a diffusion barrier for compounds such as antimicrobial agents, and also because bacteria within the biofilm are physiologically different from those in planktonic life. The mechanisms explaining the unusual resistance of biofilms to nearly all forms of sterilization are diverse and vary from nongenetic antibiotic resistance to phenotypic changes into persistent cells. ${ }^{5-10}$ Therefore, the problem of biofilm destruction demands the development of alternative methods. The use of nonthermal atmospheric-pressure plasma is one of the techniques that has been researched for more than a decade and has produced promising results. ${ }^{11-28}$

Nonthermal atmospheric-pressure plasma can be generated by an electrical discharge using different gases such as argon, helium, and air at atmospheric pressure. There are several types of electrical discharge configurations for nonthermal plasma production, and the most common are the corona, plasma jet, and dielectric barrier discharge (DBD). In the case of the DBD, an alternating or pulsed voltage is applied between two electrodes separated by a narrow gap. At least one of the electrodes is covered by a solid dielectric material (glass, plastic), or a dielectric structure is placed inside the electrode gap. There are many electrode configurations, the most common being the planar or cylindrical. The discharge can be generated in ambient air or by a gas flowing through the electrodes' gap. When the electric field at the discharge gap is high enough, it induces gas breakdown. Normally, at atmospheric pressure, a large number of individual discharge channels within the discharge gap are generated (filamentary mode). The charge carriers deposited on the surface of the dielectric reduce the electric field strength and quench the discharge. When the alternating applied voltage changes its polarity, the electric field at the discharge gap builds up and the discharge reignites. ${ }^{29}$ In the discharge channels, the gas is partially ionized and transitions to a plasma phase. In this type of discharge, the majority of the electrical energy results in the production of 
energetic electrons; the electron temperature is considerably higher than the temperature of the ions and neutrals, which remains almost at room temperature. The plasma is not in thermodynamic equilibrium and is a nonthermal plasma. The energetic electrons consume the energy by electron impact dissociation and ionization of the background gas for the production of various active agents, such as ultraviolet photons, and particles, such as neutral or excited atoms and molecules, negative and positive ions, and radicals. This type of plasma has proven to be well suited for disinfection or sterilization processes and enables the treatment of thermosensitive materials and living tissue that cannot undergo autoclaving. ${ }^{30-32}$ In a DBD operating in air, the most significant reactive species for sterilization are ozone, atomic oxygen, hydroxyl radical, and nitric oxide, among others, but the mechanism for the deactivation of microorganisms is still under discussion. ${ }^{33-35}$ The typical configuration is planar, and the discharge is applied directly onto the sample to be treated or indirectly with the sample outside the discharge region. ${ }^{27,28,33,36,37}$

Most of the studies aimed at elucidating the effects of plasmas on bacterial cells were carried out with planktonic microorganisms or spores. By the middle of the last decade, our group and a few others reported for the first time on the use of plasma for biofilm eradication. ${ }^{11,38-41}$ Since then, there has been an increasing amount of research aimed at understanding plasma-mediated biofilm inactivation, and some of the contributions have focused on Pseudomonas aeruginosa biofilms. 12,13,27,28,37,42-44

In recent years, we reported on the use of a plasma jet to inactivate $P$. aeruginosa biofilms. ${ }^{11,16,24-26} P$. aeruginosa is a Gram-negative opportunistic pathogen that preys on victims with compromised immune systems, such as patients on respirators, and causes infections of burned tissue and colonization of catheters and medical devices. It also cocolonizes, together with Burkholderia cenocepacia, lung tissue in cystic fibrosis patients, contributing to mortality. ${ }^{45}$ P. aeruginosa forms biofilms on implants and dead or living tissue, leading to a variety of persistent infections. ${ }^{46}$ Most naturally occurring biofilm are mixed species. However, single species are of particular interest due to their clinical importance. Monospecies biofilms formed by $P$. aeruginosa have become a prominent model for studying this aspect of microbial biology. ${ }^{46}$

Several approaches have been used to inactivate Pseudomonas biofilms, including the use of diverse compounds, such as antimicrobial agents, ${ }^{47,48}$ chelators,${ }^{49}$ furanone, and $N$-acyl homoserine lactones, ${ }^{50,51}$ and surface modification. ${ }^{52,53}$

In previous contributions, we demonstrated that $P$. aeruginosa biofilms grown in batch culture on borosilicate, polycarbonate, and stainless-steel surfaces were almost completely inactivated after a 5-min exposure to plasma. Atomic force microscopy studies showed that the thicknesses of the biofilms grown on borosilicate and adhesiveness to the surface were reduced. In addition, sequential morphological changes and loss of viability were observed after plasma treatment. ${ }^{25,26}$ We later presented data on plasmamediated inactivation of $P$. aeruginosa PAO1 biofilms grown on borosilicate in continuous culture. ${ }^{24}$ We showed a similar inactivation, kinetic to those reported for cells grown in batch cultures, ${ }^{25,26}$ and demonstrated that cells underwent sequential changes, ranging from minimal modification without loss of viability at short plasma exposure times to 
major structure and viability loss at longer exposure times. We reported that changes in biofilm structure leading to the loss of culturability and viability were related to a decrease in biofilm matrix adhesiveness. ${ }^{24}$ Taken together, the results show the effectiveness and applicability of plasma to inactivate biofilms grown on different abiotic surfaces and conditions. All of the experiments were carried out using an inductively coupled commercially available plasma reactor (Atomflo 300 reactor; Surfx Technologies, Redondo Beach, CA) that delivers a plasma jet and operates in helium, an expensive inert gas. ${ }^{54}$

In this article, we present an inexpensive, easy-to-build, and easy-to-handle coaxial DBD plasma source operating in air and we demonstrate its usefulness for the inactivation of Pseudomonas biofilm grown on stainless-steel coupons in continuous culture and synthetic medium. We also show results on biofilm growth under different scenarios such as three abiotic surfaces and two culture media in order to determine the conditions that produce a more robust biofilm. The best combination abiotic surface/culture medium was selected to further carry out the plasma treatments. We also demonstrate the presence of extracellular DNA released by the biofilm and the presence of living cells at exposure times for which there were no culturable cells. These results support the statement that viability experiments should always be carried out before drawing the conclusion that plasma eradicates biofilms at short exposure times based solely on counting culturable cells.

\section{MATERIALS AND METHODS}

\section{A. Plasma Generation and Conditions}

An atmospheric-pressure gas discharge plasma was produced using a DBD configuration consisting of two axial electrodes and a double dielectric barrier. A schematic of the experimental device is shown in Fig. 1. The inner electrode consisted of a 1-mmdiameter iron wire inside a 6-mm-external-diameter glass capillary tube sealed at the tip. The outer electrode was a $25-\mathrm{mm}$-long aluminum tape attached to a 1 -mm-thick acrylic $10-\mathrm{mm}$-diameter tube. The alternating current power supply was a commercially available transformer for neon light $(8 \mathrm{kV}, 70 \mathrm{~mA}$, and $50 \mathrm{~Hz})$ connected to a variable autotransformer (Variac) to control the operating voltage amplitude. The discharge operated with the power source at its maximum voltage of $8 \mathrm{kV}$ (voltage amplitude at open circuit). Each electrode was connected to one of the two high-voltage transformer outputs and was out of phase with the other ( $16 \mathrm{kV}$ between electrodes). The voltage was measured with a high-voltage probe (Tektronix $1000 \times / 3.0 \mathrm{pf} / 100 \mathrm{~mW}$ ) connected to the inner electrode. Current measurements are performed with a transformer (Bergoz CT-D5.0-B). These electrical waveforms were registered using a two-channel digitizing oscilloscope with a bandwidth of $60 \mathrm{MHz}$ and a sampling rate of $1 \mathrm{GS} / \mathrm{s}$.

The optical emission spectrum of the discharge was obtained with a spectrograph (Horiba IHR320) equipped with a charge-coupled device detector. The spectrum was analyzed and the rotational temperature determined using the transitions of the $\mathrm{N}_{2}$ second positive system. SPECAIR software was used to model the optical emission spec- 

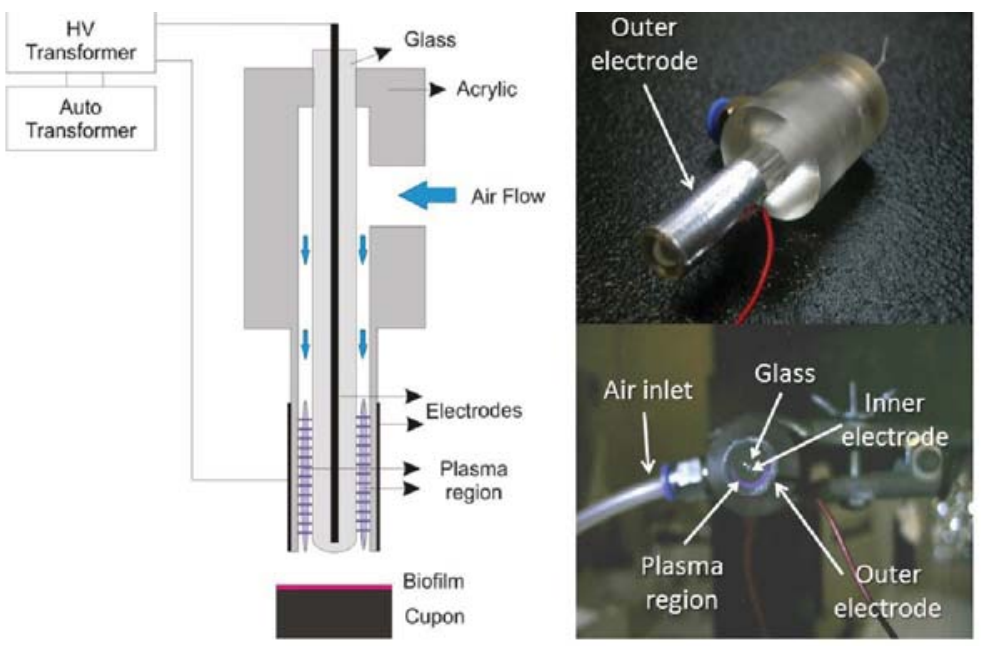

FIG. 1: Schematic and pictures of the DBD experimental device showing the axial electrodes and a double dielectric barrier. HV, High voltage.

trum and to determine the rotational temperature by comparison between the model and the experimental spectrum. ${ }^{55}$

For the biofilm experiments, the plasma applicator was mounted such that the discharge was 1 or $4 \mathrm{~mm}$ away from the biofilm. Three different setups were tested: Discharge generated in (1) airflow of $1 \mathrm{~L} / \mathrm{min},(2)$ ambient air, and (3) moistened airflow of $1 \mathrm{~L} / \mathrm{min}$. The relative humidity of the air under the first condition was $\sim 32 \% \pm 5 \%$ and $60 \%$ in the second condition, whereas it was $80 \% \pm 5 \%$ in the moistened airflow. Air was moistened by passing it through a humidifier filled with water, and airflow was determined using a commercial flow meter. Humidity was determined with an analog hygrometer (Luft48HIG-DH) at the plasma applicator gaseous output. Temperature reaching the surface of the coupon was assessed using a thermocouple.

\section{B. Strain and Culture Media}

All of the experiments were carried out with P. aeruginosa PAO1 strain cultured in either rich or minimal (also called synthetic) medium. Luria broth (LB) was used as a rich medium $^{56}$ and agrobacterium $(\mathrm{AB})$ supplemented with $0.5 \% \mathrm{w} / \mathrm{v}$ glucose as a minimal medium. ${ }^{57}$ Inocula were prepared from a fresh plate in either LB or AB medium and grown at $37^{\circ} \mathrm{C}$ with agitation in the corresponding medium.

\section{Biofilm Growth}

P. aeruginosa biofilms were grown on stainless-steel $316 \mathrm{~L}$, polycarbonate, and borosilicate (glass) 12.7-mm-diameter coupons in the CDC biofilm reactor (BioSurface Tech-

Volume 7, Issue 1, 2017 
nologies; Bozeman, MT). The biofilm reactor was inoculated with a fresh bacterial suspension in $\mathrm{LB}$ or $\mathrm{AB}$ liquid broth to reach an optical density (OD) of $0.1(550 \mathrm{~nm})$ within the reactor vessel and operated under batch culture regime for $24 \mathrm{hr}$ at $37^{\circ} \mathrm{C}$ with agitation (130 revolutions per $\mathrm{min}$ ) to obtain a dense culture. Thereafter, fresh medium was pumped through the biofilm reactor, and spent medium was removed at a constant rate. The reactor operated as a chemostat with a fixed volume of $350 \mathrm{~mL}$ until constant OD for $24 \mathrm{hr}$. The flow that ensured constant OD was $2.6 \mathrm{~mL} / \mathrm{min}$ for $\mathrm{LB}$ and $0.6 \mathrm{~mL} / \mathrm{min}$ for $\mathrm{AB}$ medium. Flow was controlled with a LKB Bromma 2120 Varioperpex pump. After running the chemostat at constant OD for $24 \mathrm{hr}$, coupons were aseptically removed from the reactor and unbound bacteria removed by rinsing the coupons twice with sterile saline solution. Coupons were air-dried for $10 \mathrm{~min}$ and then placed biofilm-side up into empty Petri dishes before the attachment assay (see Attachment Assay section below) or the plasma treatment (see Plasma Treatment section below).

\section{Attachment Assay}

Biofilm formation on the three abiotic surfaces using two culture media was indirectly assessed by determining bacterial attachment to each surface with a modification of the crystal violet method. ${ }^{58}$ Briefly, the upper surface of air-dried coupons was covered with $28 \mu \mathrm{L}$ of $1 \% \mathrm{v} / \mathrm{v}$ crystal violet for $15 \mathrm{~min}$ in the dark. The unbound crystal violet was removed, and coupons were rinsed in sterile saline solution and air-dried. Each coupon was placed in a tube with $3 \mathrm{~mL}$ of $95 \%$ alcohol to solubilize the dye, and the OD (540 $\mathrm{nm}$ ) of the solution (or appropriate dilutions) was determined. Coupons with no bacteria attached were used as controls, and 95\% alcohol was used as a blank. The absorbance of the controls was subtracted from the absorbance of the samples.

\section{E. Plasma Treatment}

P. aeruginosa biofilms were grown on stainless-steel coupons using the CDC biofilm reactor and $\mathrm{AB}$ liquid broth as described above. Air-dried coupons were subjected to gas discharge plasma for various exposure times $(1,3,5,15$, and $30 \mathrm{~min})$ under sterile conditions. A control without plasma treatment ( 0 -min exposure time) was included. Coupons were placed in a wet chamber after treatment and incubated with $35 \mu \mathrm{L}$ of sterile saline for $10 \mathrm{~min}$. Biofilms were then scraped off and suspended in $1 \mathrm{~mL}$ of sterile saline, serially diluted, and $100 \mu \mathrm{L}$ of each suspension was plated in duplicates on $\mathrm{AB}$ medium. Plates were incubated at $37^{\circ} \mathrm{C}$ and evaluated for colony-forming-unit (CFU) formation by counting the colonies.

\section{F. Bacterial Viability Determination}

Biofilms were grown on stainless-steel coupons in the $\mathrm{CDC}$ biofilm reactor using $\mathrm{AB}$ medium under the conditions described in the Biofilm Growth section above. Coupons were removed from the reactor, rinsed twice with sterile saline, air dried for $10 \mathrm{~min}$, and 
treated with humidified air plasma for 0 (control), 3, 15, and 30 min as indicated in the section immediately above.

To each coupon we added $20 \mu 1$ of $0.1-\mathrm{mg} / \mathrm{mL}$ DNAse I from bovine pancreas (Sigma-Aldrich). A control with no enzyme and no plasma treatment was included. Coupons were incubated for $60 \mathrm{~min}$ at $30^{\circ} \mathrm{C}$. After incubation, enzyme suspension was removed with sterile paper towels and coupons rinsed three times with $150 \mu \mathrm{L}$ of sterile saline. Coupons were further treated with the LIVE/DEAD ${ }^{\circledR}$ Bac Light $^{\mathrm{TM}}$ Bacterial Viability Kit (Molecular Probes), consisting of two dyes: SYTO ${ }^{\circledR} 9$ and propidium iodide. We added $20 \mu \mathrm{l}$ of a dye mixture containing a 1:2 ratio of $\mathrm{SYTO}^{\circledR} 9$ and propidium iodide to each coupon, and the coupons were incubated for $20 \mathrm{~min}$ at room temperature in the dark. Coupons were visualized with a Leica epifluorescence microscope using a 480/500-nm excitation/emission filter for $\mathrm{SYTO}^{\circledR} 9$ and a 490/635-nm excitation/emission filter for propidium iodide. Images were acquired with the Leica Application Suite (2.5.0 R1), and image analyses were performed using ImageJ software.

\section{G. Statistical Analyses}

The assumptions of normality and homoscedasticity for the analysis of variance (ANOVA) were contrasted with the Kolmogorov-Smirnov test for normality and the Levene test for homogeneity of variances. To compare means, the ANOVA and Tukey test $(\alpha=$ 0.05) were carried out using STATISTICA (StatSoft 2011) software. All of the possible combinations of medium/surface/growth conditions were statistically contrasted.

\section{RESULTS AND DISCUSSION}

\section{A. Discharge Characterization}

Electric discharge, produced in the space between the two dielectric tubes, consists of a series of filament discharges. Typical waveforms of current (I) and voltage (V) applied to the inner electrode and taken during the discharge are shown in Fig. 2. The voltage waveform has amplitude of $8 \mathrm{kV}$ and frequency of $50 \mathrm{~Hz}$, corresponding to the line frequency. The discharge current waveform has a number of current pulses of $\sim 10 \mathrm{~mA}$ and durations of $\sim 20 \mathrm{~ns}$ that are superimposed on the almost negligible displacement current of $\sim 0.01 \mathrm{~mA}$ amplitude. These I-V waveforms are characteristics of a DBD discharge with filamentary structure. The same features are shown under the three discharge conditions tested.

Figure 3 shows the simulated and experimental emission profile from the $\mathrm{N}_{2}$ second positive system (dots + lines) band between 305 and $345 \mathrm{~nm}$. The determination of best fit between the experimental spectrum and the spectrum calculated with the SPECAIR software provides the rotational temperature, an estimation of the gas temperature in the interelectrode region. ${ }^{59}$ The best fit was found at the rotational temperature of $27^{\circ} \mathrm{C}$. Such temperatures are consistent with nonthermal equilibrium plasma, where the gas is relatively cold compared to the electrons that are found at $\sim 1 \mathrm{eV}\left(11,327^{\circ} \mathrm{C}\right) .{ }^{60,61} \mathrm{Nev}$ - 


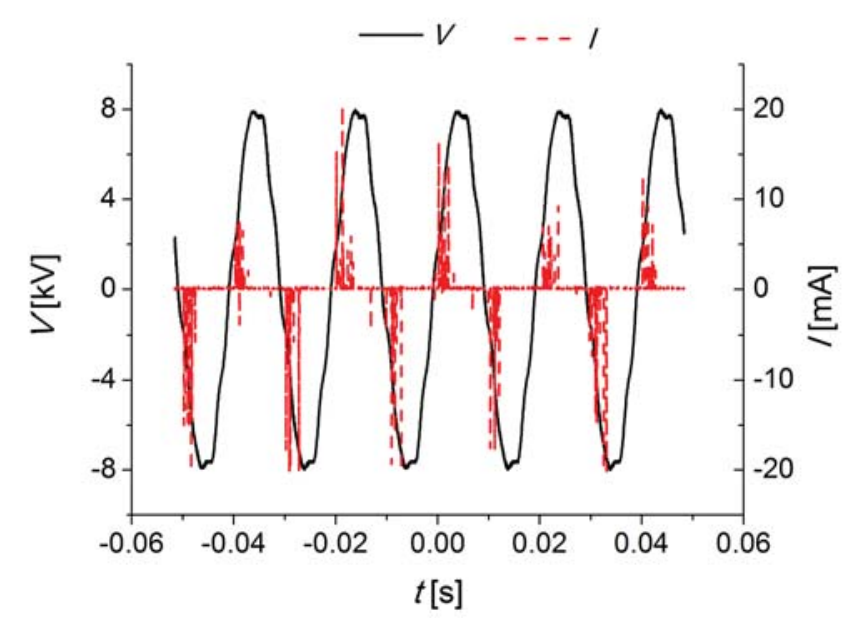

FIG. 2: Waveforms of voltage $(\mathrm{kV})$ and current $(\mathrm{mA})$ of the DBD discharge

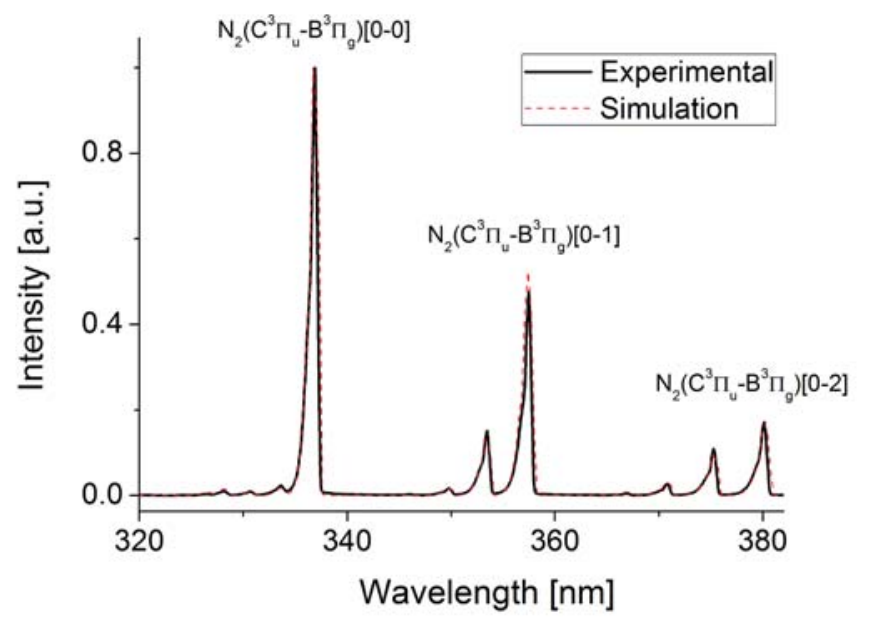

FIG. 3: Experimental spectra (solid line) and SPECAIR software spectral simulations (dashed line) of the $\mathrm{N}_{2}$ second positive system emission. The SPECAIR best fit provides a rotational temperature of $300^{\circ} \mathrm{K} \pm 20^{\circ} \mathrm{K}$.

ertheless, the temperature of the gas reaching the coupon under the three conditions tested was $30^{\circ} \mathrm{C} \pm 2^{\circ} \mathrm{C}$, as determined by the thermocouple. Therefore, temperature is not responsible for biofilm inactivation. Both the $\mathrm{I}-\mathrm{V}$ waveform and emission spectrum have the same characteristics for all of the discharge conditions tested.

\section{B. Biofilm Formation on Different Surfaces and Culture Media}

Biofilm formation was indirectly assessed under different scenarios: two culture media (rich and minimal) and three abiotic surfaces (polycarbonate, stainless steel, and glass). 
The aim of this part of the work was to find the best combination of culture medium and surface leading to the formation of a robust biofilm to be further treated with gas discharge plasma.

The following situations were statistically analyzed and compared:

1. Biofilm formation in rich medium versus minimal medium

2. Biofilm formation on diverse surfaces for each medium.

Figure 4 shows the indirect assessment of $P$. aeruginosa biofilm formation in continuous culture, on three abiotic surfaces and two culture media. It is clear from the graph that bacterial attachment depends on the abiotic surface on which the biofilm grows. Biofilm formation, measured as bacterial attachment, occurred to a significantly degree on stainless-steel coupons for both culture media.

Bacterial attachment to surfaces and subsequent biofilm formation are undoubtedly multifactorial. Bacteria may contribute surface appendages in addition to the bacterial outer envelope and metabolites produced at high cell density. Substrate surface characteristics such as roughness, hydrophobicity, or hydrophilicity are also important for attachment. In addition, components of the culture medium could also affect the substratum surface properties and consequently the adhesion process. Any substrate immersed in an aqueous fluid such as a culture medium will be rapidly covered by a film, called conditioning film, produced by the adsorption of molecules to the substrate. ${ }^{62,63}$ Conditioning films change physicochemical properties of the surface such as roughness, hydrophobicity, surface tension, charge density, and the chemical composition affecting

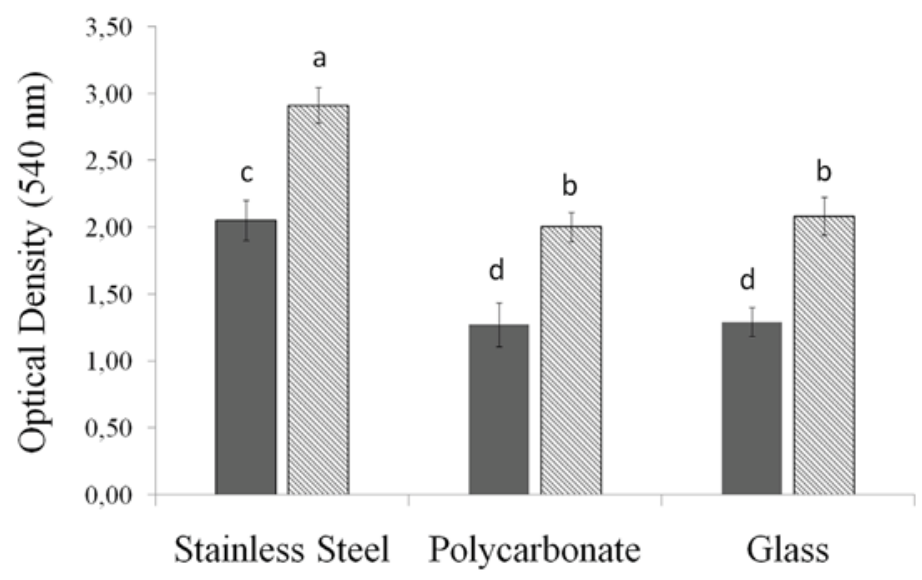

FIG. 4: Attachment assay: OD (540 nm) of a 95\% ethanol solution of crystal violet solubilized from $P$. aeruginosa biofilms. Biofilms were produced in continuous culture, on three abiotic surfaces, and two culture media, as indicated in Materials and Methods section. (Gray columns) LB medium; (hatched columns) AB medium. Results are the average of at least four independent experiments. Error bars represent the standard deviation of the mean. (a-d) Significant differences at $\alpha=0.05$.

Volume 7, Issue 1, 2017 
bacterial adhesion and further attachment. ${ }^{62-64}$ Lorite et al. demonstrated that conditioning film formation due to Periwinkle wilt culture medium decreased the degree of surface hydrophilicity and roughness of glass surfaces. ${ }^{64}$ These authors also demonstrated that the contribution of phosphate groups due to the conditioning film was more important than the changes in roughness and hydrophilicity. Chemical surface change resulted in a facilitation of biofilm growth in Xylella fastidiosa.

Several characteristics of the aqueous medium, such as $\mathrm{pH}$, nutrient levels, ionic strength, and temperature, may have a role in microbial attachment to a substratum. ${ }^{65}$ Throughout all of the abiotic surfaces and culture systems tested, the minimal medium resulted in a larger amount of cells attached and, therefore, superior biofilm formation. The rich medium is composed of glucose, tryptone, and yeast extract, whereas the synthetic culture medium consists of a mixture of ionic salts and glucose, providing a higher concentration of ions to the environment. Fletcher found that an increase in the concentration of several cations (sodium, calcium, lanthanum, ferric iron) affects the attachment of Pseudomonas fluorescens to glass surfaces, presumably by reducing the repulsive forces between the negatively charged bacterial cells and the glass surfaces ${ }^{66,67}$ The presence of sodium, calcium, ferric ion, and magnesium in the AB medium may explain the better attachment of cells to the three surfaces obtained with this medium.

It has been reported that although there is no generic pattern of attachment to test surfaces, the majority of microorganisms isolated show a preference for a hydrophobic surface. ${ }^{68}$ Hydrophobic interactions that may occur between the bacterial cell and the surface would enable the cell to overcome repulsive forces and irreversibly attach. ${ }^{65}$ Laboratory studies of the initial attachment of a marine Pseudomonad have shown that these bacteria have a preference for low-energy (hydrophobic) surfaces. ${ }^{69,70}$ Fletcher and Loeb reported low attachment of Pseudomonas spp to glass and a higher attachment to hydrophobic surfaces. ${ }^{70}$

From the three surfaces we tested, polycarbonate is hydrophobic and glass is clearly hydrophilic. As for stainless steel, based on literature contact angles, the starting surface is hydrophilic because the stainless-steel discs are milled from $316 \mathrm{~L}$ stainless-steel rods, and no surface coating or treatments are added after milling. We determined contact angles for the three materials: $70^{\circ} \pm 5^{\circ}$ for stainless steel, $55^{\circ} \pm 5^{\circ}$ for glass, and $70^{\circ}$ $\pm 5^{\circ}$ for polycarbonate. Therefore, stainless steel and polycarbonate do not differ in hydrophobicity. We cannot conclude whether the original stainless-steel coupons were hydrophilic and then became more hydrophobic, perhaps due to deposition of material in the streaks left by the machinery of the coupon.

Electrostatic forces between a cell and a potential substrate for biofilm formation play an initial part in the attachment process. Extracellular polymers may bridge the gap between bacterium and substratum, resulting in more permanent attachment. ${ }^{71}$ The bacterial cell surface interacts with the substrate surface, and both contribute to the hydrophobicity or hydrophilicity of the interaction. Most bacteria, especially those that are Gram-negative, are negatively charged but still contain hydrophobic surface com- 
ponents such as fimbriae and flagella that may help the cell to overcome the initial electrostatic repulsion between the cell and the substratum surface. ${ }^{72}$ In the case of biofilms, bacteria are assumed to have their motility genes turned off, so we do not expect a major contribution of flagella besides the initial steps.

A bacterial component that may have a role in adhesion and attachment is the exopolysaccharide excreted by biofilm-forming bacteria and part of the extracellular polymeric substances (EPS) composing the matrix. Exopolysaccharide production is affected by the nutrient status of the bacterium. It has been demonstrated that a growth medium with excess available carbon together with nitrogen, potassium, or phosphate limitation promotes exopolysaccharide synthesis. ${ }^{73,74}$ Because of its acidic structure, the exopolysaccharide binds to hydrophilic surfaces but may also associate with metal ions, divalent cations, and other components of the culture medium. ${ }^{75}$ We mentioned before that the $\mathrm{AB}$ synthetic medium used is rich in divalent cations that may interact with the EPS excreted by the biofilm.

Besides the physicochemical properties of a surface, the solid-surface characteristics are also an important factor to consider in the bigger picture of bacterial attachment to surfaces. Rougher surfaces offer an increased surface area and decreased shear forces. The extent of microbial colonization appears to increase as surface roughness increases. ${ }^{76}$ In our case, the roughness of each surface was assessed by atomic-force microscopy, and stainless steel proved to be the roughest surface because the streaks left by the machinery of the coupons were easily visible (Vandervoort and Brelles-Mariño, unpubl.). A better attachment to stainless steel compared to polycarbonate might be related to the roughness of the stainless-steel coupons that "trap" microorganisms between the streaks left by the machinery of the surface. A recent contribution by Gabriel et al. showed that even the same abiotic surface, but with distinct finishes, results in a different attachment to the material. ${ }^{13}$ The authors tested two types of stainless steel with different finishes, namely, mirror, hairline, and 2B surfaces, and found that attachment rates were significantly affected by the surface finish rather than by the stainless-steel type.

From the conditions tested, the best biofilm was obtained on a stainless-steel surface and in synthetic $\mathrm{AB}$ medium. Electrostatic forces may have a role in the initial attachment of cells to the surface, and ions present in the $\mathrm{AB}$ synthetic medium may also contribute to the process. In continuous culture, the input of fresh medium into the reactor ensures a continuous supply of nutrients, especially the carbon source, and therefore other compounds formed through bacterial metabolism may contribute to later steps of biofilm formation besides the initial attachment. The amount of matrix EPS produced will be favored by the continuous supply of the carbon source in the continuous culture. Later, hydrophobic interactions among newly synthesized compounds such as rhamnolipids and hydrophobic surfaces such as polycarbonate and stainless steel may become prevalent. The roughness of the stainless-steel surface may promote a better bacterial attachment to the surface. Based on the results obtained, the conditions resulting in better biofilms were $\mathrm{AB}$ medium and stainless steel coupons. Therefore, plasma treatment was performed on coupons with biofilms grown in continuous culture under those conditions.

Volume 7, Issue 1, 2017 


\section{Survival Curves and Inactivation Kinetics}

Preliminary experiments were carried out using biofilms treated with plasma generated in air at a flow of $1 \mathrm{~L} / \mathrm{min}$. Almost no colonies were recovered after the treatment. To determine whether cells were killed by plasma or dried out by the simple flow of air, the same experiments were repeated with no discharge ignition and using solely air at the same flow. Only very few cells survived after the air treatment, demonstrating that cells were dehydrated by the simple flow of air and not killed by plasma (data not shown). As dehydrated cells remain alive and recover once hydrated, we no longer continued experiments with plasma ignited in air at $1-\mathrm{L} / \mathrm{min}$ flow and moved to the other experimental setups: plasma operating in ambient air with no flow or in moistened air at 1-L/ min flow. The rationale for using moistened air was based on the fact that preliminary experiments with no plasma ignition and performed with dry or moistened air at various airflows showed a higher cell survival for the latter, regardless of the flow. Biofilm inactivation was not due to temperature either, because temperatures measured on the surface of the coupon were $30^{\circ} \mathrm{C} \pm 2^{\circ} \mathrm{C}$.

Figures 5 and 6 depict the survival curves for $P$. aeruginosa biofilms grown in synthetic $\mathrm{AB}$ medium on stainless-steel coupons and treated with plasma operating in ambient air (Fig. 5) or with a moistened airflow of $1 \mathrm{~L} / \mathrm{min}$ (Fig. 6). The experiments with plasma operating in ambient air were carried out at two distances from the plasma applicator to the sample: 1 and $4 \mathrm{~mm}$, whereas only the distance of $4 \mathrm{~mm}$ was used for

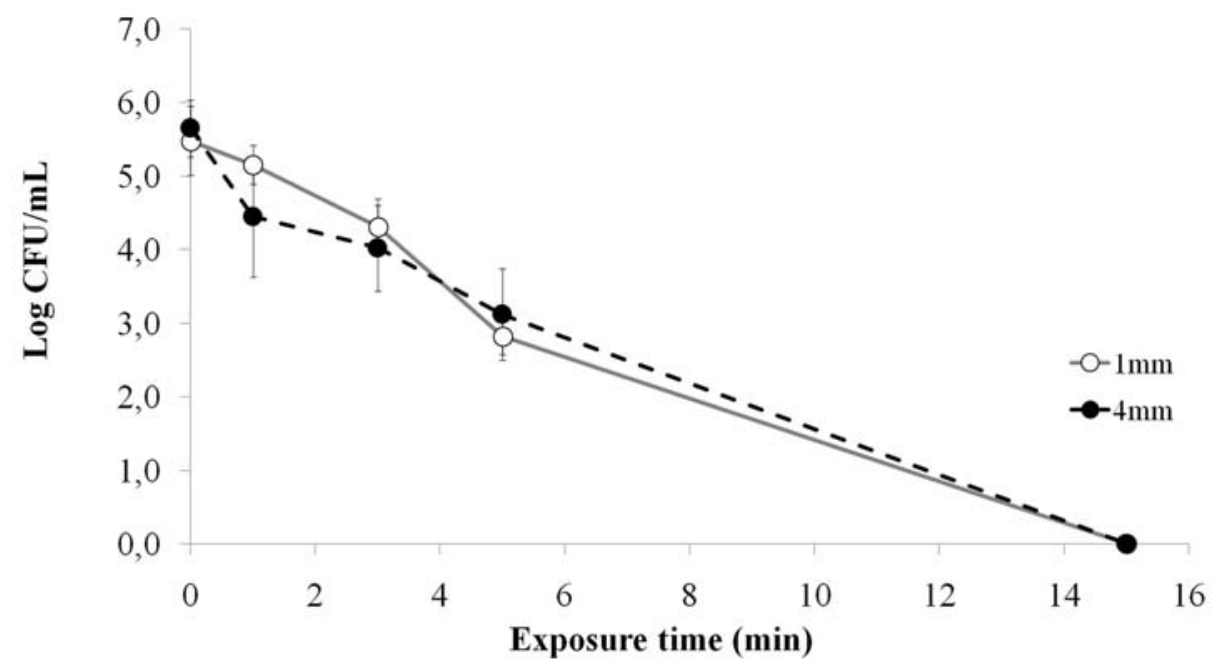

FIG. 5: Survival curve: $\log$ of the number of CFU $/ \mathrm{mL}$ vs. plasma exposure time. P. aeruginosa biofilms grown in continuous culture on stainless-steel coupons in $\mathrm{AB}$ synthetic medium were treated with DBD plasma generated in ambient air. The plasma source was located 1 or $4 \mathrm{~mm}$ from the sample surface. Results are the average of four independent experiments, and each experiment was performed in duplicate. Error bars represent the standard error of the mean. 


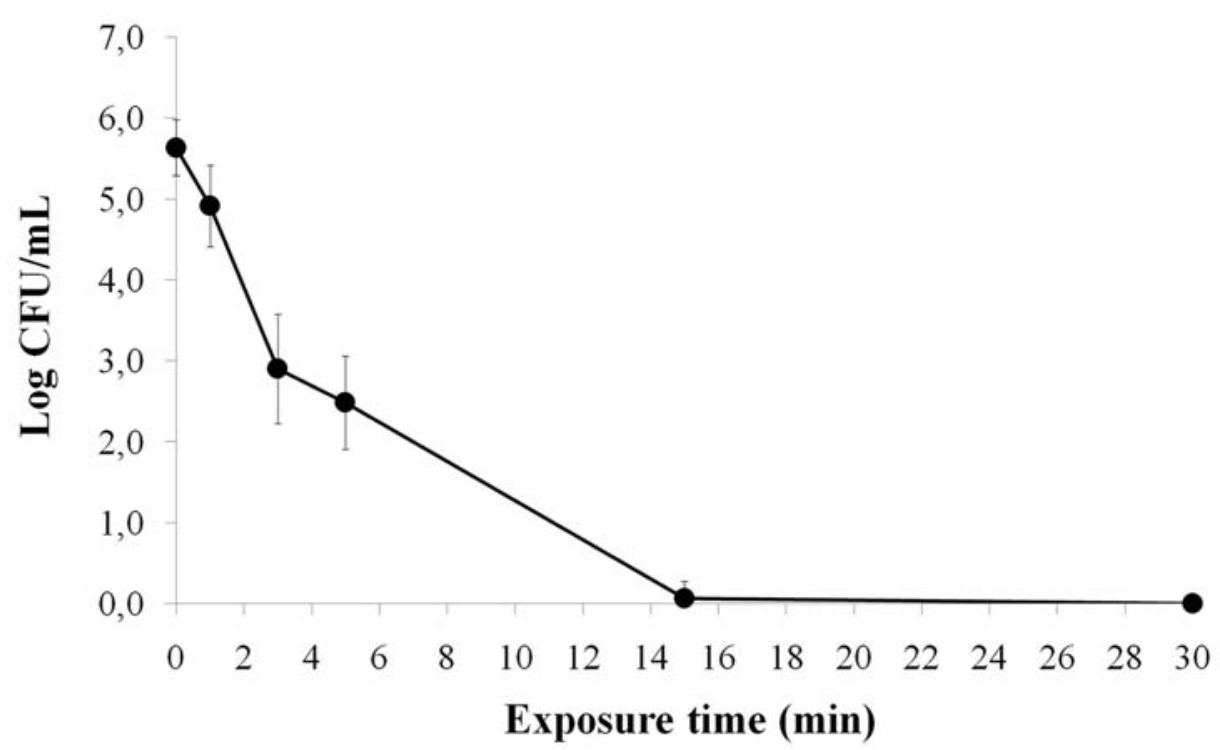

FIG. 6: Survival curve: $\log$ of the number of $\mathrm{CFU} / \mathrm{mL}$ vs. exposure time. P. aeruginosa biofilms grown in continuous culture on stainless-steel coupons in $\mathrm{AB}$ synthetic medium were treated with DBD plasma generated in moistened air at a flow of $1 \mathrm{~L} / \mathrm{min}$. The plasma source was located $4 \mathrm{~mm}$ from the sample surface. Results are the average of four independent experiments, and each experiment was performed in duplicate. Error bars represent the standard error of the mean.

experiments with moistened air. Because there were no significant differences in the concentration of culturable cells treated with plasma operating in ambient air for the two distances used, and both D values (see below) were similar, a 4 mm-distance was chosen for the experiments with moistened air because of practical operative reasons (easier coupon manipulation). Cell concentration at a 0 -min exposure time corresponds to the control without plasma treatment.

The graphs show that $P$. aeurginosa biofilms grown on stainless-steel coupons in continuous culture in $\mathrm{AB}$ medium were completely eradicated after a 15-min treatment with plasma for both treatment conditions, namely, ambient air and a moistened airflow of $1 \mathrm{~L} / \mathrm{min}$, resulting in a CFU/mL decrease of $5.6 \log _{10}$ units $(>99.999 \%$ killing efficacy). For plasma generated in ambient air, a CFU/mL decrease of $1.6 \log _{10}$ units was determined for a 3-min exposure to plasma, whereas a decrease of $2.7 \log _{10}$ units was determined for the same plasma exposure time using moistened air. These results demonstrate that moistened air inactivates biofilms more rapidly than ambient air. CFU/coupon decreases of 5.50, 6.88, and $4.20 \log _{10}$ were obtained, respectively, for Escherichia coli O157:H7 (ATCC 438), Cronobacter sakazakii (ATCC 29004), and Staphylococcus aureus (KCCM 40050) biofilms using an underwater DBD plasma source operating in dry air. ${ }^{77}$ In this case, the biofilms were treated for $90 \mathrm{~min}$. Reductions of $5.8 \log _{10}$ were obtained for $P$. aeruginosa biofilms treated with $\mathrm{O}_{2}-\mathrm{N}_{2}$ plasma for $60 \mathrm{~min}^{12}$ Therefore, our methodology provides an excellent killing efficacy with shorter exposures to plasma.

Volume 7, Issue 1, 2017 
A good measure of the removal efficiency is the determination of decimal reduction time (D value), the time required to reduce an original concentration of microorganisms by $90 \%$. This parameter has been originally defined for thermal killing of microorganisms by autoclaving. For plasma generated in ambient air, results show a constant decline in CFU/mL, with a D value of $2.78 \pm 0.14 \mathrm{~min}$ for the $1-\mathrm{mm}$ distance and a $\mathrm{D}$ value of $2.49 \pm 0.38 \mathrm{~min}$ for the 4 -mm distance. Single-slope kinetics was reported by Ziuzina et al. for Listeria monocytogenes biofilms treated with atmospheric cold plasmas produced in a DBD configuration. ${ }^{28}$ In a recent contribution by Gabriel et al., single-slope kinetics and D values on the order of 2-3 s were reported for $P$. aeruginosa biofilms grown on stainless-steel surfaces and treated with an air-based microwave plasma jet. ${ }^{13}$ However, these authors incubated the bacterial inoculum for just $4 \mathrm{hr}$ and, even if they had a biofilm and not a simple layer of attached cells, it is likely easier to remove such a young structure compared to a mature biofilm. In addition, the reported $\mathrm{D}$ values were obtained at temperatures of $143.42^{\circ} \mathrm{C}$ to $174.05^{\circ} \mathrm{C}$, much higher than those achieved in our work.

For the plasma generated in moistened air, the survival curve shows a typical doubleslope kinetics. Therefore, two D values were determined: one for short exposure times $\left(D_{1}\right)$ and another for the portion of the curve showing a slower decline $\left(D_{2}\right) \cdot D_{1}$ measured $1.14 \pm 0.28 \mathrm{~min}$, and $\mathrm{D}_{2} 4.36 \pm 0.63 \mathrm{~min}$. This inactivation kinetics is similar to what has been previously described. ${ }^{25,26}$ Vandervoort and Brelles-Mariño reported double-slope kinetics for $P$. aeruginosa biofilms grown on borosilicate coupons under continuous culture: $\mathrm{D}_{1}$ measured $27 \mathrm{~s}$ and $\mathrm{D}_{2} 6.13 \mathrm{~min} .{ }^{24}$ Zelaya et al. reported double-slope kinetics for $P$. aeurginosa biofilm grown in batch cultures, although $\mathrm{D}$ values were not calculated. ${ }^{25}$ In that work, results showed a clear decrease in the percentage of surviving cells versus time, regardless of the biofilm age. The same group reported similar results for Chromobacterium violaceum biofilms grown for 4 or $7 \mathrm{~d}$ on polystyrene microtiter plates. ${ }^{11,16}$

The removal efficiency of the treatments can be assessed by comparing D values. The D value corresponding to biofilms treated with plasma generated in ambient air is twice as high as $\mathrm{D}_{1}$ obtained for biofilms treated with plasma generated in moistened air. The difference might be due to the presence of more reactive oxygen and nitrogen species and ozone in the moistened air plasma. Purevdorj et al. studied plasma-mediated killing of spore-forming Bacillus pumilus. ${ }^{22}$ In this case, spore mortality varied depending on the composition of the gas feed and was higher with moistened air plasma, suggesting that the inactivation may occur through hydroxyl radicals generated from water molecules.

In Vandervoort and Brelles-Mariño's contribution with P. aeruginosa biofilms grown in continuous culture, the decrease in the percentage of viable cells was more dramatic than the results we report here, because there were almost no culturable cells after a 5-min treatment with plasma, and most of the inactivation occurred during a biofilm exposure to plasma of $<1 \mathrm{~min}$. However, it was also reported that cells retained viability and virulence at short periods of exposure to plasma, even though cells were not culturable. ${ }^{24}$ Moreover, it is important to point out that previous work was carried out using a commercially available radiofrequency plasma jet operating in helium, which is an expensive inert gas. 
Here, we propose a plasma source prototype operating in simple moistened air, which makes the design affordable, easy to build, and easy to use but still effective.

\section{Viability Experiments}

Epifluorescence microscopy and the LIVE/DEAD ${ }^{\circledR}$ BacLight ${ }^{\mathrm{TM}}$ Bacterial Viability Kit allow one to assess plasma-treated biofilm cell viability by monitoring viability as a function of the membrane integrity of the cell. The LIVE/DEAD assay consists of a mixture of two dyes: the green fluorescent nucleic acid stain SYTO ${ }^{\circledR} 9$ and the red fluorescent nucleic acid stain propidium iodide. Both stains differ in their ability to penetrate bacterial membranes. When used alone, SYTO 9 stains cells with both intact and damaged membranes, whereas propidium iodide penetrates only bacteria with damaged membranes. Propidium iodide competes with SYTO 9 stain for nucleic acid binding sites when both dyes are present. Therefore, when mixed in recommended proportions, bacteria with intact cell membranes fluoresce green, and bacteria with damaged membranes fluoresce red. Thus, the ratio of green to red fluorescence provides an estimation of bacterial viability.

Figure 7 shows the fluorescent images of biofilms stained with the LIVE/DEAD ${ }^{\circledR}$ Bac Light ${ }^{\mathrm{TM}}$ Bacterial Viability Kit. These images correspond to biofilms not exposed to
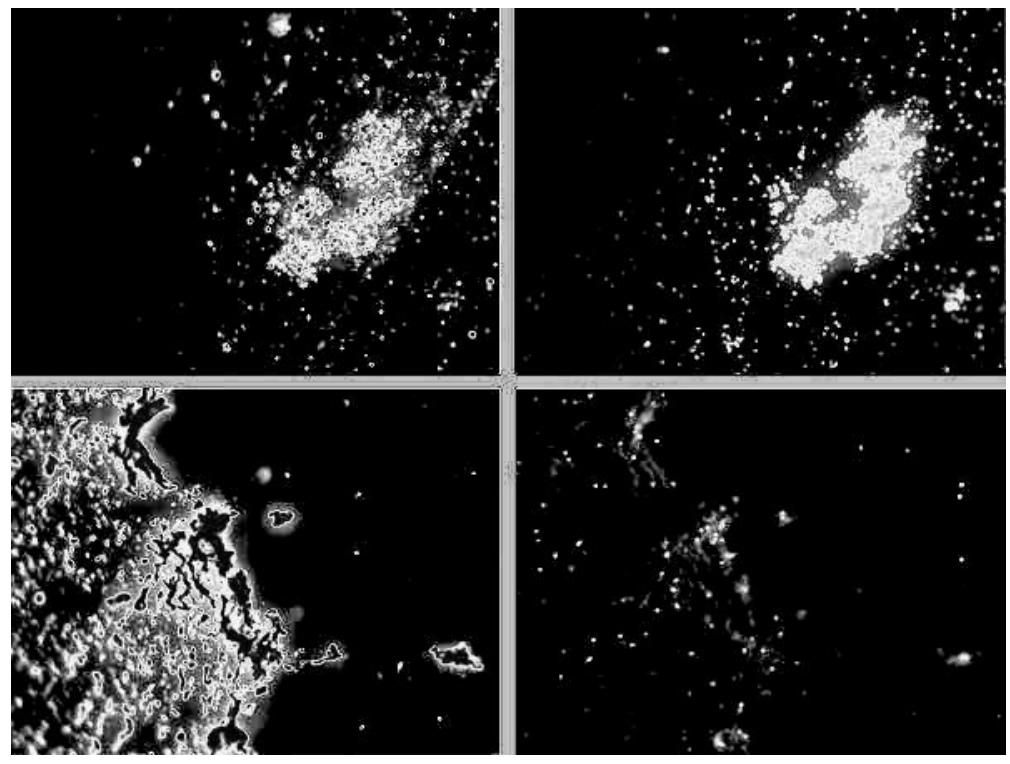

FIG. 7: Fluorescence microscopy images of biofilms: Biofilms grown as indicated in Materials and Methods section were stained with LIVE/DEAD ${ }^{\circledR}$ Bac Light ${ }^{\mathrm{TM}}$ Bacterial Viability Kit and visualized using the 480/500-nm excitation/emission filter for SYTO ${ }^{\circledR} 9$ (left) and the 490/635$\mathrm{nm}$ excitation/emission filter for propidium iodide (right). (Upper panels) Biofilms with no DNAse treatment; (lower panels) biofilms treated with DNAse for 60 min before staining. 
plasma (control). Therefore, most of the cells were thought to be alive and, thus, green. The upper panel depicts control biofilms with no DNAse treatment visualized using the 480/500-nm excitation/emission filter for $\mathrm{SYTO}^{\circledR} 9$ (Fig. 7, left) and the 490/635-nm excitation/emission filter for propidium iodide (Fig. 7, right). As can be seen in the upper right image, the cells stain red, although we were not expecting to have a dead biofilm before the plasma treatment. We hypothesized that cells were not actually dead and that the red staining was due to extracellular DNA (eDNA) released from the biofilm and masking the cells that were alive.

Biofilm-forming strains of $P$. aeruginosa, including PAO1, have been shown to produce eDNA that may function as part of the biofilm matrix. ${ }^{78}$ Evidence has been presented that suggests that eDNA functions as a cell-to-cell interconnecting compound in $P$. aeruginosa biofilms. ${ }^{43,78}$ Allesen-Holm et al. have studied the distribution of eDNA on $P$. aeruginosa $\mathrm{PAO} 1$ biofilms grown in $\mathrm{AB}$ medium and have obtained similar results to those shown in Fig. 7, upper panel. ${ }^{43}$ The researchers reported that DNAse treatment dissolved young $P$. aeruginosa biofilms, whereas established biofilms were only marginally affected by the treatment. This suggests that the cells in young biofilms are held together by eDNA, whereas the cells in older biofilms are held together primarily by other compounds. Based on these reports, we decided to treat the biofilms with DNAse before staining, and results are shown in Fig. 7, lower panel. It is clear by comparing images on the left (green-stained biofilm) and right (few red cells) that the biofilm had most of its cells alive and the red color shown on the upper panel on the right side was due to eDNA and not dead cells.

Figure 8 shows the fluorescent images of biofilms subjected to plasma treatment for $0,3,15$, and $30 \mathrm{~min}$, treated with DNAse for $60 \mathrm{~min}$, and stained with the LIVE/ DEAD $^{\circledR}$ BacLight ${ }^{\mathrm{TM}}$ Bacterial Viability Kit. As can be seen in the images, biofilms are predominantly green for the control and the 3-min treatment; therefore, cells are alive. The coupon subjected to a 30-min plasma treatment shows a completely red-stained biofilm, and, therefore, cells are dead. As for the biofilm treated with plasma for $15 \mathrm{~min}$, although most of the cells are red and dead, live green cells are still visible. It is important to note that the survival curves (Figs. 5 and 6) showed no culturable cells after 15 min of exposure to plasma. However, the LIVE/DEAD ${ }^{\circledR}$ Bac Light $^{\mathrm{TM}}$ demonstrates the presence of living cells that may eventually multiply. These results support our previous statement that viability experiments should always be carried out before drawing the conclusion that plasma eradicates biofilms at short exposure times, based solely on counting culturable cells. ${ }^{16,24}$

\section{CONCLUSION}

In summary, results show that the coaxial DBD plasma source operating in air is a useful tool for the inactivation of Pseudomonas biofilms grown on stainless-steel coupons in continuous culture and synthetic medium. The coaxial DBD plasma source was used to generate the discharge, either in ambient air or in moistened air. For the latter, we report an inactivation kinetics similar to that in previously described results. ${ }^{24,26}$ We also 


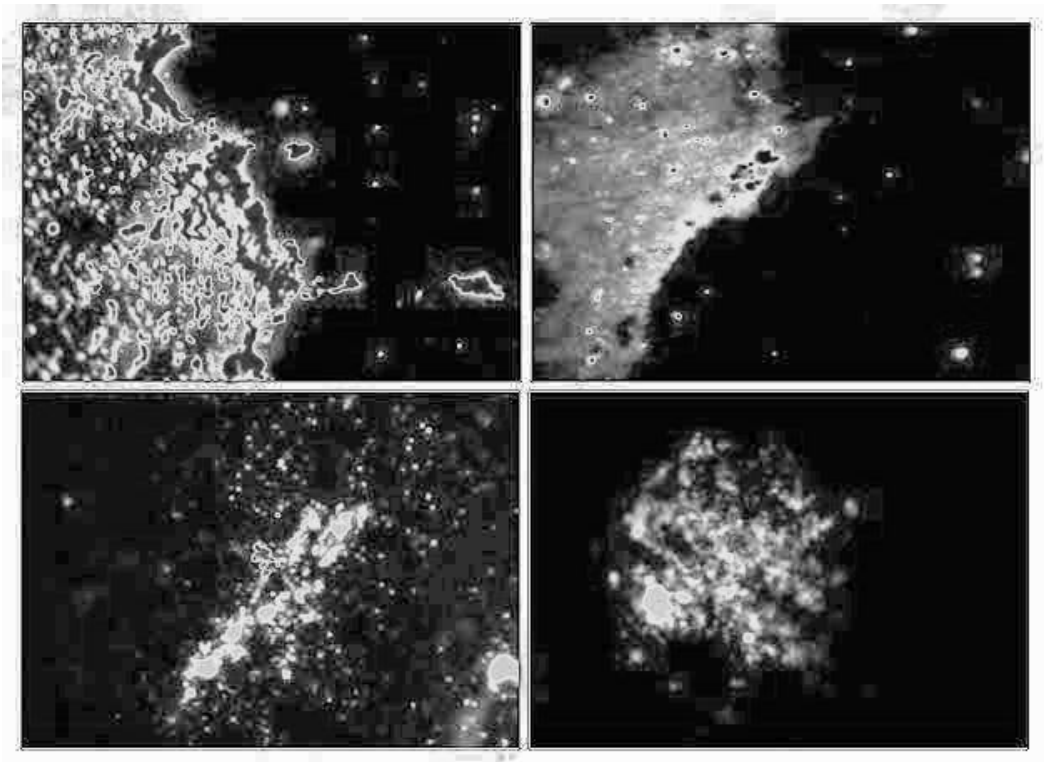

FIG. 8: Fluoresence microscopy of plasma-treated biofilms. Biofilms grown as indicated in the Materials and Methods sections were subjected to plasma treatment for $0,3,15$, and $30 \mathrm{~min}$, treated with DNAse for $60 \mathrm{~min}$, and stained with a LIVE/DEAD ${ }^{\circledR}$ Bac Light ${ }^{\mathrm{TM}}$ Bacterial Viability Kit. (Upper panels) 0 and 3 min of plasma treatment, left and right image, respectively; (lower panels) 15 and 30 min of plasma treatment, left and right image, respectively. Images were superimposed from images obtained using the 480/500-nm excitation/emission filter for SYTO ${ }^{\circledR} 9$ and the 490/635-nm excitation/emission filter for propidium iodide.

demonstrated the presence of extracellular DNA on Pseudomonas biofilms grown in continuous culture and that biofilms treated with plasma for relatively short exposure times retain viability, even in the case of lack of cell culturability. Our results support the statement that viability experiments are indispensable before drawing the conclusion that plasma eradicates biofilms based solely on cell culturability.

The coaxial DBD presented in this work represents a more affordable, easy-to-build, and easy-to-handle but still effective plasma source, because it operates in air and does not rely on the use of helium or other expensive inert gases. In addition, the search for the best combination of culture medium and surface material leading to a robust biofilm before plasma treatment has not been previously assessed.

\section{ACKNOWLEDGMENTS}

This work was supported by Agencia Nacional de Promoción Científica y Tecnológica, Argentina, PICT-2009-0047 (Graciela Brelles-Mariño); Consejo Nacional de Investigaciones Científicas y Técnicas (CONICET) PIP GI11220120100453; and the University of Buenos Aires (UBA) 20020130100699BA Project (D.G. and L.G.). Juliana SolerArango and Magalí Xaubet are indebted to CONICET for fellowships. The authors 
thank Dr. Kurt Vandervoort (Department of Physics and Astronomy, California State Polytechnic University, Pomona) for editing and critically reviewing the manuscript.

\section{REFERENCES}

1. Kolter R, Losick R. One for all and all for one. Science. 1998;280:226-7.

2. Stoodley P, Sauer K, Davies DG, Costerton JW. Biofilms as complex differentiated communities. Annu Rev Microbiol. 2002;56:187-209.

3. Costerton JW, Stewart PS, Greenberg EP. Bacterial biofilms: A common cause of persistent infections. Science. 199;284:1318-22.

4. Park SR, Mackay WG, Reid DF. Helicobacter sp recovered from drinking water biofilm samples from a water distribution system. Water Res. 2001;35:1624-6.

5. Brelles-Mariño G. Challenges in biofilm inactivation: The use of cold plasma as a new approach. J Bioproces Biotech. 2012;2:4. Available from: http://www.omicsonline.org/2155-9821/2155-98212-e107.pdf

6. Hoyle BD, Costerton JW. Bacterial resistance to antibiotics: The role of biofilms. Progr Drug Res. 1991;37:91-105.

7. Leriche V, Briandet R, Carpentier B. Ecology of mixed biofilms subjected daily to a chlorinated alkaline solution: Spatial distribution of bacterial species suggests a protective effect of one species to another. Environ Microbiol. 2003;5:64-71.

8. Saravanan P, Nancharaiah YV, Venugopalan VP, Rao TS, Jayachandran S. Biofilm formation by Pseudoalteromonas ruthenica and its removal by chlorine. Biofouling. 2006;22:371-8.

9. Stewart PS. Mechanisms of antibiotic resistance in bacterial biofilms. Int J Med Microbiol. 2002;292:107-13.

10. Stewart PS, Costerton JW. Antibiotic resistance of bacteria in biofilms. Lancet. 2001;358:135-8.

11. Abramzon N, Joaquin JC, Bray JD, Brelles-Mariño, G. Biofilm destruction by RF high-pressure cold plasma jet. IEEE Trans Plasma Sci. 2006;34:1304-9.

12. Ben Belgacem Z, Carré G, Boudifa M, Charpentier E, Cawe B, Gellé MP. Effectiveness of non-thermal $\mathrm{O}_{2}-\mathrm{N}_{2}$ plasma on P. aeruginosa multilayer biofilms cultured on hydroxyapatite. IRBM. 2016;37:68-74.

13. Gabriel AA, Ugay MCCF, Siringan MAT, Rosario LMD, Tumlos RB, Ramos HJ. Atmospheric pressure plasma jet inactivation of Pseudomonas aeruginosa biofilms on stainless steel surfaces. Innov Food Sci Emerg. 2016;36:311-9.

14. Heaselgrave W, Shama G, Andrew PW, Kong MG. Inactivation of Acanthamoeba spp. and other ocular pathogens by application of cold atmospheric gas plasma. Appl Environ Microbiol. 2016;82:3143-8.

15. Hoffmann C, Berganza C, Zhang J. Cold Atmospheric plasma: Methods of production and application in dentistry and oncology. Med Gas Res. 2013;3:21.

16. Joaquin J, Kwan C, Abramzon N, Vandervoort K, Brelles-Mariño G. Is gas-discharge plasma a new solution to the old problem of biofilm inactivation? Microbiology. 2009;175:724-32.

17. Modic M, McLeod NP, Sutton JM, Walsh JL. Cold atmospheric pressure plasma elimination of clinically important single- and mixed-species biofilms. Int J Antimicrob Ag. 2017;49:375-8.

18. Moisan M, Barbeau J, Moreau S, Pelletier J, Tabrizian M, Yahia LH. Low-temperature sterilization using gas plasmas: A review of the experiments and an analysis of the inactivation mechanisms. Int $\mathrm{J}$ Pharm. 2001;226:1-21.

19. Moisan M, Barbeau J, Crevier MC, Pelletier J, Philip N, Saoudi B. Plasma sterilization: Methods and mechanisms. Pure Appl Chem. 2002;74:349-58.

20. Pignata C, D'Angelo D, Fea E, Gilli G. A review on microbiological decontamination of fresh produce with nonthermal plasma. J Appl Microbiol. 2017;122(6):1438-1455.

21. Puligundla P, Mok C. Potential applications of nonthermal plasmas against biofilm-associated microorganisms in vitro. J Appl Microbiol. 2017;122(5):1134-1148. 
22. Purevdorj D, Igura N, Ariyada O, Hayakawa I. Effect of feed gas composition of gas discharge plasmas on Bacillus pumilus spore mortality. Lett Appl Microbiol. 2003;37:31-4.

23. Scholtz V, Pazlarova J, Souskova H, Khun J, Julak J. Nonthermal plasma-A tool for decontamination and disinfection. Biotechnol Adv. 2015;33:1108-19.

24. Vandervoort KG, Brelles-Mariño G. Plasma-mediated inactivation of Pseudomonas aeruginosa biofilms grown on borosilicate surfaces under continuous culture system. PLoS ONE. 2014;9(10):e108512.

25. Zelaya A, Stough G, Rad N, Vandervoort K, Brelles-Mariño G. Pseudomonas aeruginosa biofilm inactivation: Decreased cell culturability, adhesiveness to surfaces, and biofilm thickness upon highpressure non-thermal plasma treatment. IEEE Trans Plasma Sci. 2010;38:3398-403.

26. Zelaya A, Vandervoort K, Brelles-Mariño G. Battling bacterial biofilms with gas discharge plasma. In: Machala Z, Hensel K, Akishev Y, editors. NATO Science for Peace and Security Series. Plasma for biodecontamination, medicine and food security. Dordrecht, Germany: Springer; 2012. p. 135-48.

27. Ziuzina D, Patil S, Cullen PJ, Boehm D, Bourke P. Dielectric barrier discharge atmospheric cold plasma for inactivation of Pseudomonas aeruginosa biofilms. Plasma Med. 2014;4:137-52.

28. Ziuzina D, Boehm D, Patil S, Cullen PJ, Bourke P. Cold plasma inactivation of bacterial biofilms and reduction of quorum sensing regulated virulence factors. PLoS ONE. 2015;10:e0138209.

29. Kogelschatz U. Dielectric-barrier discharges: Their history, discharge physics, and industrial applications. Plasma Chem Plasma Process. 2003;23:1-46.

30. Fridman G. Non-equilibrium plasmas in biology and medicine. In: Brelles-Mariño G, editor. Biological and environmental applications of gas discharge plasmas. New York: Nova Science Publishers; 2010. p. 99-188.

31. Mertens N, Viöl W. Dielectric barrier discharge: A versatile tool for biological applications. In: BrellesMariño G, editor. Biological and environmental applications of gas discharge plasmas. New York: Nova Science Publishers; 2010. p. 237-62.

32. Sladek REJ, Fioloche SK, Sissons CH, Stoffels E. Treatment of Streptococcus mutans biofilms with a non-thermal atmospheric plasma. Lett Appl Microbiol. 2007;45:318-23.

33. Cheng H, Liu X, Lu,X, Liu D. Active species delivered by dielectric barrier discharge filaments to bacteria biofilms on the surface of apple. Phys Plasma. 2016;23:073517.

34. Gaunt LF, Beggs CB, Georghiou GE. Bactericidal action of the reactive species produced by gas-discharge nonthermal plasma at atmospheric pressure: A review. IEEE Trans Plasma Sci. 2006;34(4):1257-69.

35. Laroussi M. Nonthermal decontamination of biological media by atmospheric-pressure plasmas: Review, analysis, and prospects. IEEE Trans Plasma Sci. 2002;30:1409-15.

36. Klämpfl TG, Isbary G, Shimizu T, Li YF, Zimmermann JL, Stolz W, Schlegel J, Morfill GE, Schmidt HU. Cold atmospheric air plasma sterilization against spores and other microorganisms of clinical interest. Appl Environ Microbiol. 2012;78:5077-82.

37. Matthes R, Bender C, Schlüter R, Koban I, Bussiahn R, Reuter S, Lademann J, Weltmann KD, Kramer A. Antimicrobial efficacy of two surface barrier discharges with air plasma against in vitro biofilms. PLoS ONE. 2013;8:e70462.

38. Akishev YS, Grushin ME, Karalnik VB, Monich AE, Pan'kin MV, Trushkin NI, Kholodenko V, Chugunov V, Zhirkova N, Irkhina I, Kobzev EO. Sterilization/decontamination of physiological solution and dry surface by non-thermal plasma created in bubbles and jet. In: Proceedings of the 2nd International Workshop on Cold Atmospheric Pressure Plasmas: Sources and Applications CAPPSA; Bruges, Belgium; 2005. p. 69-72.

39. Akishev Y, Grushin M, Karalkin V, Trushkin N, Kholodenko V, Chugunov V, Kobzev E, Zhirkova N, Irkhina I, Kireev G. Atmospheric-pressure, nonthermal plasma sterilization of microorganisms in liquids and on surfaces. Pure Appl Chem. 2008;80:1953.

40. Becker K, Koutsospyros A, Yin SM, Christodoulatos C, Abramzon N, Joaquin JC, Brelles-Mariño G. Environmental and biological applications of microplasmas. Plasma Phys Control Fusion. 2005;47:B513-23.

Volume 7, Issue 1, 2017 
41. Brelles-Mariño G, Joaquin JC, Bray JD, Abramzon N. Gas discharge plasma as a novel tool for biofilm destruction. In: Proceedings of the 2nd International Workshop on Cold Atmospheric Pressure Plasmas: Sources and Applications CAPPSA; Bruges, Belgium; 2005. p. 69-72.

42. Alkawareek MY, Algwari QTh, Laverty G, Gorman SP, Graham WG, O'Connell D, Gilmore BF. Eradication of Pseudomonas aeruginosa biofilms by atmospheric pressure non-thermal plasma. PloS ONE. 2012;7(8):e44289.

43. Allesen-Holm M, Barken KB, Yang L, Klausen M, Webb JS, Kjelleberg S, Molin S, Givskov M, Tolker-Nielsen T. A characterization of DNA release in Pseudomonas aeruginosa cultures and biofilms. Mol Microbiol. 2006;59:1114-28.

44. Mai-Prochnow A, Bradbury M, Ostrikov K, Murphy AB. Pseudomonas aeruginosa biofilm response and resistance to cold atmospheric pressure plasma is linked to the redox-active molecule phenazine. PLoS ONE. 2015;10(6):e0130373.

45. Tümmler B, Kiewitz C. Cystic fibrosis: An inherited susceptibility to bacterial respiratory infections. Mol Med Today. 1999;5:351-8.

46. Davey ME, Caiazza NC, O'Toole GA. Rhamnolipid surfactant production affects biofilm architecture in Pseudomonas aeruginosa PAO1. J Bacteriol. 2003;185:1027-36.

47. Gillis RJ, Iglewski BH. Azithromycin retards Pseudomonas aeruginosa biofilm formation. J Clin Microbiol. 2004;42:5842-5.

48. Tanaka G, Shigeta M, Komatsuzawa H, Sugai M, Suginaka H, Usui T. Effect of clarithromycin on Pseudomonas aeruginosa biofilms. Chemotherapy. 2000;46:36-42.

49. Banin E, Vasil ML, Greenberg EP. Iron and Pseudomonas aeruginosa biofilm formation. Proc Natl Acad Sci. 2005;102:11076-81.

50. Davies D, Parsek M, Pearson J, Iglewski B, Costerton JW, Greenberg, EP. The use of signal molecules to manipulate the behavior of biofilm bacteria. Clin Microbial Infect. 1999;5:5S7-8.

51. Hentzer M, Riedel K, Rasmussen TB, Heydorn A, Andersen JB, Parsek MR, Rice SA, Eberl L, Molin S, Høiby N, Kjelleberg S, Givskov M. Inhibition of quorum sensing in Pseudomonas aeruginosa biofilm bacteria by a halogenated furanone compound. Microbiology. 2002;148:87-102.

52. Balazs DJ, Triandafillu K, Wood P, Chevolot Y, van Delden C, Harms H, Hollenstein C, Mathieu JH. Inhibition of bacterial adhesion on PVC endotracheal tubes by RF-oxygen glow discharge, sodium hydroxide and silver nitrate treatments. Biomaterials. 2003;11:2139-51.

53. Bryers JD, Ratner BD. Bioinspired implant materials befuddle bacteria. ASM News. 2004;70: $232-7$.

54. Schutze JY, Jeong SE, Park J, Selwyn GS, Hicks RF. The atmospheric plasma jet: A review and comparison to other plasma sources. IEEE Trans Plasma Sci. 1998;26:1685-94.

55. Laux CO, Spence TG, Kruger CH, Zare RN. Optical diagnostics of atmospheric pressure air plasmas. Plasma Sources Sci Technol. 2003;12:125-38.

56. Bertani G. Studies on lysogenesis. I. The mode of phage liberation by lysogenic Escherichia coli. J Bacteriol. 1951;62:293-300.

57. Clark DJ, Maaløe O. DNA replication and the division cycle in Escherichia coli. J Mol Biol. 1967;23:99-112.

58. O'Toole GA, Kolter R. Flagellar and twitching motility are necessary for Pseudomonas aeruginosa biofilm development. Mol Microbiol. 1998;30:295-304.

59. Staack D, Farouk B, Gutsol AF, Fridman AA. Spectroscopic studies and rotational and vibrational temperature measurements of atmospheric pressure normal glow plasma discharges in air. Plasma Sources Sci Technol. 2006;15:818-27.

60. Kushner M, Kong M. Fundamentals of non-equilibrium plasma. In: Laroussi M, Kong M, Morfill G, Stoltz W, editors. Plasma medicine. Cambridge: Cambridge University Press; 2012. p. 7-27.

61. Walsh JL, Kong MG. 10 ns Pulsed atmospheric air plasma for uniform treatment of polymeric surfaces. Appl Phys Lett. 2007;91:251504.

62. Hohmann S, Kögel S, Brunner Y, Schmieg B, Ewald C, Kirschhöfer F, Brenner-Weiß G, Länge K. 
Surface acoustic wave (SAW) resonators for monitoring conditioning film formation. Sensors. 2015;15(5):11873-88.

63. Kirschhöfer F, Rieder A, Prechtl C, Kühl B, Sabljo K, Wöll C, Obst U, Brenner-Weiß. Quartz crystal microbalance with dissipation coupled to on-chip MALDI-ToF mass spectrometry (QCM-D-MALDI) as a tool for characterising proteinaceous conditioning films on functionalised surfaces. Analyt Chim Acta. 2013;802:95-102.

64. Lorite GS, Rodrigues CM, de Souza AA, Kranz C, Mizaikoff B, Cotta MA. The role of conditioning film formation and surface chemical changes on Xylella fastidiosa adhesion and biofilm evolution. $\mathbf{J}$ Colloid Interface Sci. 2011;359:289-95.

65. Donlan RM. Role of biofilms in antimicrobial resistance. ASAIO J. 2002;46:S47-52.

66. Fletcher M. The applications of interference reflection microscopy to the study of bacterial adhesion to solid surfaces. In: Houghton DR, Smith RN, Eggins RN, Eggins HOW, editors. Biodeterioration. London: Elsevier Applied Science; 1988. p. 31-5.

67. Fletcher M. Attachment of Pseudomonas fluorescens to glass and influence of electrolytes on bacterium-substratum separation distance. J Bacteriol. 1998;170:2027-30.

68. Pringle JH, Fletcher M. Influence of substratum wettability on attachment of freshwater bacteria to solid surfaces. Appl Environ Microbiol. 1983;45:811-7.

69. Fletcher ML, Floodgate GD. An electron microscopic demonstration of an acidic polysaccharide involved in the adhesion of a marine bacterium to solid surfaces. J Gen Microbiol. 1973;74:326-34.

70. Fletcher M, Loeb GI. Influence of substratum characteristics on the attachment of a marine Pseudomonad to solid surfaces. Appl Environ Microbiol. 1079;37:67-72R.

71. Marshall KC, Stout R, Mitchell R. Mechanism of the initial events in the sorption of marine bacteria to surfaces. J Gen Microbiol. 1971;68:337-48.

72. Corpe WA. Microbial surface components involved in adsorption of microorganisms onto surfaces. In: Bitton G, Marshall KC, editors. Adsorption of microorganisms to surfaces. New York: John Wiley \& Sons; 1980. p. 105-44.

73. Brelles-Mariño G, Boiardi JL. Nitrogen limitation of chemostat-grown Rhizobium etli elicits higher infection-thread formation in Phaseolus vulgaris. Microbiology. 1996;142:1067-70.

74. Sutherland IW. Biofilm exopolysaccharides: A strong and sticky framework. Microbiology. 2001;147:3-9.

75. Flemming HC, Wingender J, Griegbe T, Mayer C. Physico-chemical properties of biofilms. In: Evans LV, editor. Biofilms: Recent advances in their study and control. Amsterdam: Harwood Academic Publishers; 2000. p. 19-34.

76. Characklis WG, McFeters GA Marshall KC. Physiological ecology in biofilm systems. In: Characklis WG, Marshall KC, editors. Biofilms. New York: John Wiley \& Sons; 1990. p. 341-94.

77. Khan MSI, Lee EJ, Kim YJ. A submerged dielectric barrier discharge plasma inactivation mechanism of biofilms produced by Escherichia coli O157:H7, Cronobacter sakazakii, and Staphylococcus aureus. Sci Rep. 2016;6:37072.

78. Whitchurch CB, Tolker-Nielsen T, Ragas PC, Mattick JS. Extracellular DNA required for bacterial biofilm formation. Science. 2002;295(5559):1487. 